\title{
Supporting information for Leaching of estrogenic hormones from manure-treated structured soils
}

Jeanne Kjær*, Preben Olsen, Kamilla Bach, Heidi C. Barlebo, Flemming Ingerslev, Martin Hansen, Bent Halling Sørensen

* To whom correspondence should be addressed: E-mail: jkj@geus.dk. Phone: +45 3814 2333. Fax: +4538142050 .

This PDF file includes:

1. Material supporting the Introduction

2. Figure S1. Location of the Silstrup and Estrup field sites

3. Table S1. Physical and chemical properties of selected soil profiles at the Silstrup and Estrup field sites.

4. Quality assurance data for chemical analysis including Figure S2 showing control charts.

5. Table S2. Literature reports of laboratory batch studies comparing aerobic and anaerobic dissipation of E1 and E2.

5. References 


\section{Material supporting the Introduction}

The sorption capacity of E1 and E2 is generally high, with $\log \mathrm{K}_{\mathrm{oc}}$ being in the range 2.93.8 and 2.9-4.1, respectively (1-6). In batch experiments, E2 usually dissipates rapidly. Under aerobic conditions, $\mathrm{DT}_{50}$ in soil ranges from a few hours to a few days (4,6-9). Similar rapid transformation of E2 has been reported in transport experiments with repacked soil columns (1-3).

In mineralization studies conducted in three agricultural soils ranging widely in texture and chemical properties, less than $18 \%(7)$ and $10 \%$ (9) of the applied E2 was mineralized to $\mathrm{CO}_{2}$ within 90 days. In spite of rapid dissipation it seems that the majority of the applied E2 is retained in the soil as either the intact substance, bound residues or degradation products. The primary degradation product of E2 is E1, while other metabolites are uncommon (9).

E1 also dissipates rapidly. In one study (8), rapid disappearance of E2 was accompanied by transient accumulation of E1, although the latter dissipated within 1-3 days. In transport studies with repacked soil columns $(1,2)$ and aerobic batch experiments with agricultural topsoils (4), both E2 and E1 dissipated in a similar manner. Dissipation of E1 in particular is reported to be highly affected by redox conditions (4). Under aerobic conditions E2 (applied as $2.5 \mathrm{mg} / \mathrm{kg}$ soil) was rapidly biotransformed into E1 (DT ${ }_{50} 3$ days), and the generated E1 dissipated to an undetectable level of $0.1 \mathrm{mg} / \mathrm{kg}$ within three days. Under anaerobic conditions, however, E2 was transformed much more slowly (DT 5020 days) and 
the generated E1 persisted in the soil without further dissipation throughout the 70-day experiment.

High subsurface retention in sandy to sandy loam soil has been reported under field conditions (10). Since E2 and E1 were absent in tile drainage water and most groundwater wells thought to be affected by dairy wastewater, it was concluded that groundwater discharged from tile drains is not a major source of E1 and E2 input to surface water and that E1 and E2 are effectively removed during subsurface transport due to the fact that average transport time from source to the groundwater wells was in the order of weeks to months. 


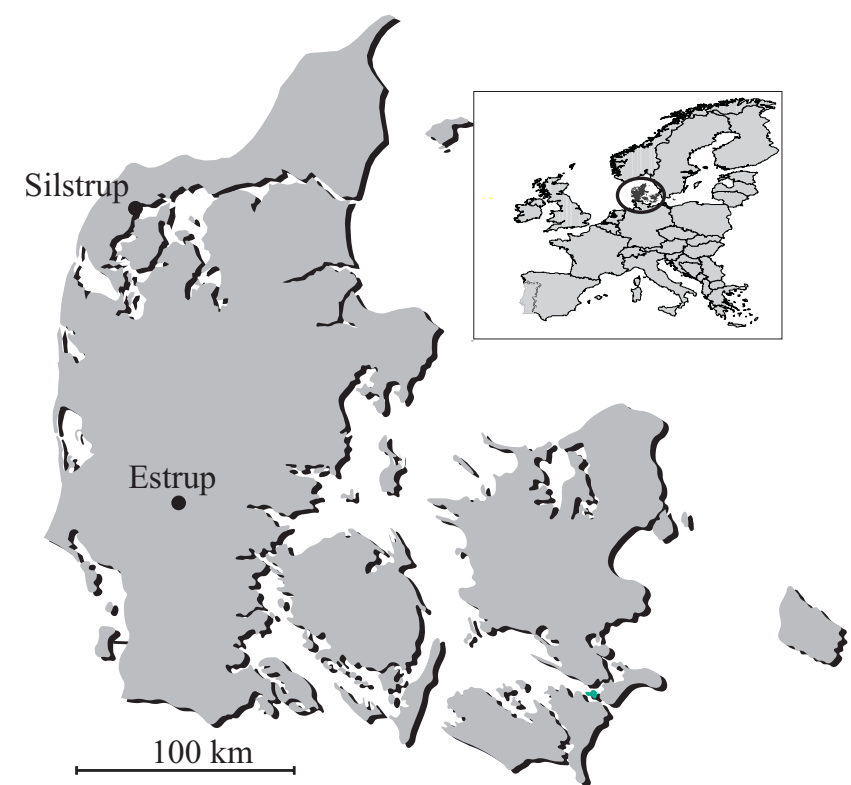

FIGURE S1. Location of the Silstrup and Estrup field sites. 
TABLE S1. Physical and chemical properties of selected soil profiles at the Silstrup and Estrup field sites.

\begin{tabular}{|c|c|c|c|c|c|c|c|c|c|c|c|}
\hline Profile $^{\dagger}$ & Horizon & Depth & $\begin{array}{c}\text { Clay } \\
(\%)\end{array}$ & $\begin{array}{l}\text { Silt } \\
(\%)\end{array}$ & $\begin{array}{c}\text { Sand } \\
(\%)\end{array}$ & $\begin{array}{l}\mathrm{OM} \\
(\%)\end{array}$ & $\mathrm{C} / \mathrm{N}$ & $\begin{array}{l}\text { CEC } \\
(\text { meq } 100 \\
\left.\mathrm{g}^{-1}\right)\end{array}$ & $\mathrm{pH}_{\mathrm{CaCl} 2}$ & $\begin{array}{c}\mathrm{K}_{\mathrm{s}} \\
\left(\mathrm{m} \mathrm{s}^{-1}\right)\end{array}$ & Structure \\
\hline \multicolumn{12}{|l|}{ Estrup 2} \\
\hline & Ap & $0-26$ & 13.8 & 12.7 & 70.8 & 2.7 & 13 & 12.1 & 6.5 & $2.0 \mathrm{e}^{-6}$ & Moderately coarse subangular \\
\hline & $\mathrm{Bt}(\mathrm{g})$ & $26-45$ & 36.3 & 15.3 & 47.8 & 0.5 & 6 & 13.9 & 6.3 & $1.0 \mathrm{e}^{-7}$ & Moderately coarse prismatic \\
\hline & $\mathrm{Bt}(\mathrm{g}) 2$ & $45-121$ & 33.0 & 15.9 & 50.9 & 0.2 & 4 & 16.8 & 6.6 & nd & Moderately coarse prismatic \\
\hline & $\mathrm{Cc}^{\S 1}$ & $121-150$ & 31.1 & 24.9 & 7.5 & 0.5 & 6 & 19.7 & 7.5 & $1.6 \mathrm{e}^{-8}$ & Very strong and coarse angular \\
\hline
\end{tabular}

Estrup 3

$\begin{array}{lccccccccc}\text { Ap } & 0-28 & 9.9 & 7.1 & 77.5 & 5.5 & 17 & 15 & 7.0 & 5.1 \mathrm{e}^{-6} \text { Moderately subangular } \\ \text { Bs/Bhs } & 28-58 & 8.8 & 4.7 & 85.7 & 0.8 & 12 & 10.2 & 6.6 & 5.4 \mathrm{e}^{-8} \text { Moderately angular } \\ \mathrm{Bt}(\mathrm{g}) & 58-115 & 12.2 & 4.3 & 83.1 & 0.4 & 8 & 9.2 & 4.2 & \text { nd } \\ \mathrm{2C} & 115-185 & 38.9 & 24.1 & 26.9 & 10.1 & 39 & 40.5 & 4.5 & 3.1 \mathrm{e}^{-8} \text { Massive }\end{array}$

Silstrup 2

\begin{tabular}{|c|c|c|c|c|c|c|c|c|c|c|}
\hline Ap & $0-30$ & 24.6 & 15.4 & 57.2 & 2.8 & 10 & 20.4 & 7.0 & $5.2 \mathrm{e}^{-8}$ & Moderately coarse granular \\
\hline $\mathrm{Bv}$ & $30-60$ & 27.9 & 14.1 & 57.5 & 0.5 & 6 & 19.3 & 7.2 & $4.1 \mathrm{e}^{-5}$ & Strong coarse angular \\
\hline $\mathrm{Bv}(\mathrm{g})$ & $60-95$ & 25.9 & 14.1 & 59.6 & 0.4 & 5 & 12.1 & 7.4 & nd & Strong coarse angular \\
\hline $\mathrm{Cc} \$ 2$ & $95-132$ & 17.5 & 10.5 & 72.0 & - & - & 8.3 & 7.7 & $2.6 \mathrm{e}^{-7}$ & Strong coarse angular \\
\hline $\mathrm{Cc}(\mathrm{g})^{\S 3}$ & $132-190$ & 34.5 & 11.5 & 53.9 & 0.1 & 1 & 21.2 & 7.7 & nd & Strong coarse angular \\
\hline
\end{tabular}

nd.: Not determined; OM: Organic matter, determined as 1.72 x total organic carbon;

$K_{s}:$ Saturated hydraulic conductivity determined on small soil columns (6.1 cm diameter, $\left.100 \mathrm{~cm}\right)(11)$;

${ }^{\dagger}$ According to the USDA Soil Taxonomy (12) selected profiles are classified as Abruptic Argiudoll (Estrup 2), Fragiaquic

Glossudalf (Estrup 3) and Typic Hapludoll (Silstrup 2).

${ }^{\ddagger}$ Clay: $<2 \mu m$; Silt: 2-20 $\mu \mathrm{m}$; Sand: $20-2,000 \mu \mathrm{m}$.

$\mathrm{CaCO}_{3}$ content (\%): ${ }^{\S 1} 36.1^{\S 2} 28.3,{ }^{\S 3} 15.4$. 


\section{Quality assurance data for chemical analysis}

In connection with every series of samples a set of quality control samples were analysed along with the real samples, i.e. taken through the total analytical procedure. The set of quality control samples consisted of one blank sample (tap water) and two identical control samples (tap water and drainage water from the test sites) to which a mixture of the two estrogens estrone and $\beta$-estradiol (E1 and E2) had been added at a level $2.78 \mathrm{ng} / 1$ of each analyte. Results from the control samples are collected in quality control charts (Figure S2) displaying the mean values of the two control samples for each series of samples (X-chart) as well as the difference between duplicate results (Rchart).

Based on the control charts (Figure S2 \& S3) the overall precision (RSD, reproducibility) was found to be $30 \%$ (E2) and $17 \%(\mathrm{E} 1)$ and the accuracy of the analytic methods $86 \%$ (E2) and $95 \%$ (E1). The accuracy of the analytic methods was estimated by comparing the nominal $(2.78 \mathrm{ng} / \mathrm{l})$ and the measured mean concentration (2.40 ng E2/1 and $2.65 \mathrm{ng} \mathrm{E1/1).} \mathrm{The} \mathrm{latter} \mathrm{estimated} \mathrm{as} \mathrm{an} \mathrm{average} \mathrm{of}$ the total number of measurement shown in Figure S2 and S3. The Limit of Detection (LOD) is defined by the formula:

$\mathrm{LOD}=\mathrm{t} 0.995(\mathrm{f}) \cdot \mathrm{Sw}$ where $\mathrm{Sw}$ is the standard deviation determined in the same series of samples (repeatability) at concentrations near LOD and t0.995(f) is between 3 and 4 with more than 6 repetitions. The LOD was determined by an 8 -fold determination of tap water spiked with $0.2 \mathrm{ng} / \mathrm{L}$ of each of the 4 components. This resulted in calculated LODs well below $0.1 \mathrm{ng} / \mathrm{L}$ on which basis a general LOD of 0.1 was determined. 

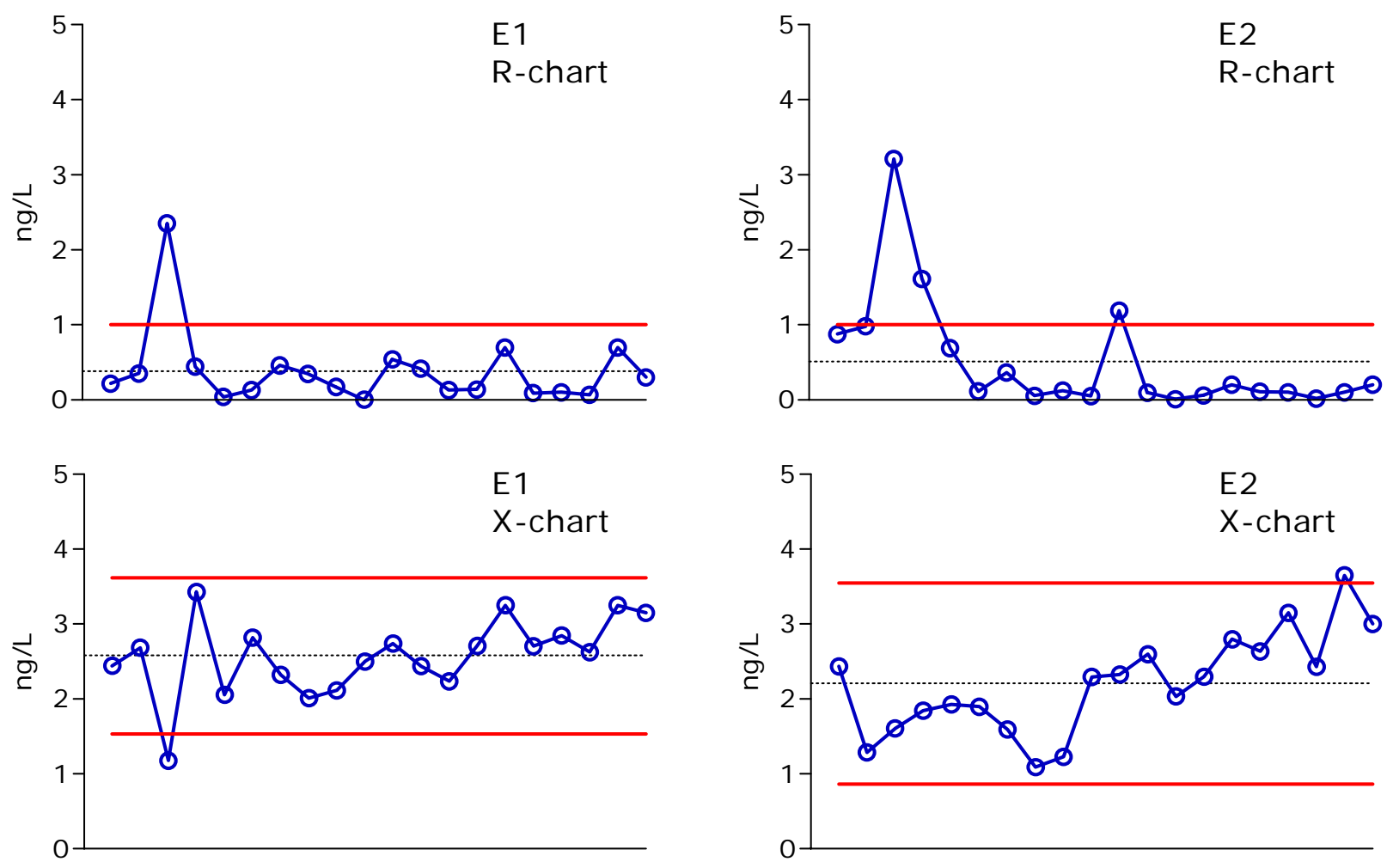

91

92

Figure S2. Control chart showing results from analytical chemical determination of E1 (left) and E2(right) in quality control samples. Upper graph shows the difference of duplicate measurements (R-charts) and lower graph the chart shows mean values (X-chart). Solid red lines indicated 95,5\% confidence limits and dotted black lines the mean values of the measured control samples. 

and $\mathrm{E} 2$.

Reference and

soil type

(4)

Agricultural topsoil Aerobic $\quad \mathrm{DT}_{50}=3$ days

Anaerobic $\quad \mathrm{DT}_{50}=20$ days
The E1 generated dissipated to the undetectable level of $0.1 \mathrm{mg} / \mathrm{kg}$ within 3 days.

The E1 generated persisted in the soil without further dissipation throughout the 70-day experiment.

(13)

River bed material Aerobic $\mathrm{DT}_{50}=0.11$ days $\mathrm{DT}_{50}=0.42$ days

Anaerobic $\mathrm{DT}_{50}=0.37-0.66$ days

The E1 generated persisted in the soil without further dissipation throughout the 2-day experiment.

(14)
Aquifer material
Aerobic
$\mathrm{DT}_{50}=2$ days
Not analyzed
Anaerobic
$\mathrm{DT}_{50}=107$ days
Not analyzed 


\section{Literature cited}

1. Das, B. S.; Lee, L. S.; Rao, P. S. C.; Hultgren, R. P. Sorption and degradation of steroid hormones in soils during transport: Column studies and model evaluation. Environ. Sci. Technol. 2004, 38 (5), 1460-1470.

2. $\quad$ Casey, F. X. M.; Simunek, J.; Lee, J.; Larsen, G. L.; Hakk, H. Sorption, mobility, and transformation of estrogenic hormones in natural soil. J. Environ. Qual. 2005, 34 (4), 1372-1379.

3. Casey, F. X. M.; Larsen, G. L.; Hakk, H.; Simunek, J. Fate and transport of 17 beta-estradiol in soil-water systems. Environ. Sci. Technol. 2003, 37 (11), 2400-2409.

4. Ying, G. G.; Kaakana, R. S. Sorption and degradation of estrogen-like-endocrine disrupting chemicals in soil. Environ. Toxicol Chem. 2005, 24 (10), 2640-2645.

5. Yu, Z. Q.; Xiao, B. H.; Huang, W. L.; Peng, P. Sorption of steroid estrogens to soils and sediments. Environ. Toxicol Chem. 2004, 23 (3), 531-539.

6. Lee, L. S.; Strock, T. J.; Sarmah, A. K.; Rao, P. S. C. Sorption and dissipation of testosterone, estrogens, and their primary transformation products in soils and sediment. Environ. Sci. Technol. 2003, 37 (18), 4098-4105.

7. Colucci, M. S.; Bork, H.; Topp, E. Persistence of estrogenic hormones in agricultural soils: I. 17 beta-estradiol and estrone. J. Environ. Qual. 2001, 30 (6), 2070-2076.

8. Colucci, M. S.; Topp, E. Dissipation of pert-per-trillion concentrations of estrogenic hormones from agricultural soils. Can. J. Soil Sci. 2002, 82 335-340.

9. Jacobsen, A. M.; Lorenzen, A.; Chapman, R.; Topp, E. Persistence of testosterone and 17 beta-estradiol in soils receiving swine manure or municipal biosolids. J. Environ. Qual. 2005, 34 (3), 861-871.

10. Kolodziej, E. P.; Harter, T.; Sedlak, D. L. Dairy wastewater, aquaculture, and spawning fish as sources of steroid hormones in the aquatic environment. Environ. Sci. Technol. 2004, 38 (23), 6377 6384.

11. Iversen, B. V.; Schjønning, P.; Poulsen, T. G.; Moldrup, P. In Situ, on-site and laboratory measurements of soil air permability: Boundary conditions and measurement scale. Soil Sci. 2001, 166 (2), 97-106. 
12. Soil Survey Staff Soil Taxonomy. A Basic system for Soil Classification for Maling and Interpretating Soil Surveys, Agricultural Handbook Number 436, Second Edition. Agricultural Handbook Number 436, Second Edition. 1999, United States Department of Agriculture, New Tork .

13. Jurgens, M. D.; Holthaus, K. I. E.; Johnson, A. C.; Smith, J. J. L.; Hetheridge, M.; Williams, R. J. The potential for estradiol and ethinylestradiol degradation in English rivers. Environ. Toxicol Chem. 2002, 21 (3), 480-488.

14. Ying, G. G.; Kookana, A. R. S.; Dillon, P. Sorption and degradation of selected five endocrine disrupting chemicals in aquifer material. Water Res. 2003, 37 (15), 3785-3791. 